\title{
Patient and Partner Strategies for Talking about Lifestyle Change Following a Cardiac Event
}

\author{
Daena J. Goldsmith \\ Jennifer J. Bute \\ Kristin A. Lindholm
}

[This is an Accepted Manuscript of an article published by Taylor \& Francis Group in Journal of Applied Communication Research on November 25, 2011, available online: http://dx.doi.org/10.1080/00909882.2011.636373]

Author Note

Daena J. Goldsmith is Professor of Rhetoric \& Media Studies at Lewis \& Clark College, Portland, OR; Jennifer J. Bute is Assistant Professor of Communication Studies at Indiana University -- Purdue Unviersity, Indianapolis, IN; and Kristin A. Lindholm is Associate Professor of Communication at Trinity International University, Deerfield, IL. Preliminary analyses related to this paper were presented at the meeting of the National Communication Association, November 2007, Chicago, IL. This research was supported by a grant from the University of Illinois Campus Research Board. We are grateful to the cardiac rehabilitation staff at Carle Foundation Hospital and Provena Covenant Medical Center and the Champaign-Urbana chapter of Mended Hearts for their assistance in participant recruitment. We thank Virginia McDermott and Kristen Bauer for their assistance with interviews and transcription.

Correspondence to: Daena J. Goldsmith, Department of Rhetoric \& Media Studies, Lewis \& Clark College, 0615 SW Palatine Hill Rd., Portland, OR, 97219 (daena@lclark.edu).

This is an Accepted Manuscript of an article published by Taylor \& Francis Group in Journal of Applied Communication Research on November 25, 2011, available online: http://dx.doi.org/10.1080/00909882.2011.636373 


\begin{abstract}
Heart patients are frequently advised to make lifestyle changes and communication with a romantic partner can help or hinder adoption of heart healthy behaviors. However, talking about lifestyle change can have both positive and negative meanings and this can create dilemmas for couples. We engaged in interpretive analysis of interviews with 25 patients and 16 partners to identify the ways they managed the meanings of lifestyle change talk. Their communicative strategies included rationing talk, saying it nicely and framing it cooperatively. Each strategy had advantages and disadvantages as well as optimal conditions. We also identified interpretive lenses that shaped the meaning of talk, including legitimacy, patience, emphasizing the positive, moderation, benefits for both people, and perceived compliance. Finally, environmental resources (such as household patterns and communication with the social network) contextualized the meaning of talk. We proposed a model of the interrelated influence of communication, interpretation, and environment on the meanings of talking about lifestyle change.

KEYWORDS: lifestyle change, marital communication, social support, communication dilemmas, strategic communication, cardiac disease
\end{abstract}

This is an Accepted Manuscript of an article published by Taylor \& Francis Group in Journal of Applied Communication Research on November 25, 2011, available online: http://dx.doi.org/10.1080/00909882.2011.636373 
Patient and Partner Strategies for Talking about Lifestyle Change Following a Cardiac Event When one person in a marriage or committed relationship goes through a heart attack or bypass surgery, life changes for both people. Patients and partners face the demands of a patient's hospitalization and recovery as well as the physical and symbolic adjustments entailed in rehabilitation and ongoing disease management. It is good news for couples that many patients resume an active life (Ell \& Dunkel-Schetter, 1994) and that they can significantly enhance recovery and lower risk through changes in diet, exercise, smoking, and stress-management (Miller, Taylor, Davidson, Hill, \& Krantz, 1990). Couple communication can facilitate these changes. For example, partners may discuss how to implement lifestyle changes and provide support and encouragement. Several interventions have targeted couple interaction as a key component of successful patient rehabilitation and lifestyle modification (e.g., Daugherty, Saarmann, Riegel, Sornborger, \& Moser, 2002; Rankin-Esquer, Deeter, Froelicher, \& Taylor, 2000; Sher \& Baucom, 2001).

Yet the promise of better living through partner-supported lifestyle change is not without limitations. Studies suggest as few as 25 to 40 percent of patients sustain lifestyle changes after six months, and these figures continue to decrease further after the first year (Burke, DunbarJacob, \& Hill, 1997; Haynes, 2001; Miller, Hill, Kottke, \& Ockene, 1997). It is not clear that involving partners improves the likelihood of success. Some forms of communication facilitate lifestyle changes whereas other ways of talking can backfire (Cohen \& Lichtenstein, 1990; Franks et al., 2006; Lewis \& Rook, 1999; Tucker \& Anders, 2001; Tucker \& Mueller, 2000). Because it is apparent that partner involvement does not always facilitate patient lifestyle change, we studied how couples talk and interpret their talk about lifestyle change. We focused

This is an Accepted Manuscript of an article published by Taylor \& Francis Group in Journal of Applied Communication Research on November 25, 2011, available online: http://dx.doi.org/10.1080/00909882.2011.636373 
on couples in the first year following one person's cardiac event (defined here as a myocardial infarction, MI, or coronary artery bypass graft surgery, CABG) and their talk about heart-healthy lifestyle recommendations (diet, appropriate levels of activity and exercise, smoking cessation, stress management). Whereas most previous research on this topic has attempted to predict outcomes and to identify the optimal way for couples to interact, our study led us to conclude that there is not a single best way to talk. Instead, we develop a model that can help theorists, practitioners, and couples to understand the communication strategies, interpretive lenses, and environmental resources through which patients and partners make sense of their experiences.

\section{Couple Talk about Lifestyle Change Following a Cardiac Event}

Studies of the effects of partner interaction on patient lifestyle change have produced divergent findings. Describing how patients and partners talk and how they interpret their talk can explain the conflicting findings of previous quantitative studies and provide a new model of couple interaction about lifestyle change.

Numerous studies have examined whether social support from a partner increases a patient's likelihood of making lifestyle changes (for reviews see Daly et al., 2002; Goldsmith, Gumminger, \& Bute, 2006; Rankin-Esquer et al., 2000). Partner support can include rewarding healthful behavior, giving tangible help to make changing behavior easier, encouraging new behaviors, or validating a new identity that includes healthful behavior. Support can also make lifestyle changes seem worth undertaking. Patients are more likely to make lifestyle changes if they believe it is important to their partner (McMahon, Miller, Wikoff, Garrett, \& Ringel, 1986; Miller, McMahon, Ringel, Siniscalchi, \& Welsh, 1989).

However, partner attempts to encourage healthful behavior are not uniformly successful.

This is an Accepted Manuscript of an article published by Taylor \& Francis Group in Journal of Applied Communication Research on November 25, 2011, available online: http://dx.doi.org/10.1080/00909882.2011.636373 
Some studies find a neutral or negative relationship between partner support and patient change (for a review, see Goldsmith, Gumminger, \& Bute, 2006). A determination to support lifestyle change can evolve into partner over-involvement, resulting in patient resistance or helplessness (Coyne, Wortman, \& Lehman, 1988) and undermining patient self-efficacy to resume activities or engage in self-management (Coyne, Ellard, \& Smith, 1990). Simply measuring the presence or amount of partner involvement does not consistently predict good outcomes.

Knowing how patients and partners communicate is central to understanding when couple interaction promotes or inhibits patient lifestyle change. Recent studies of young (presumably healthy) couples show partner attempts to encourage a healthful lifestyle take many forms, including positive and negative, bilaterial and unilateral, and direct and indirect tactics (e.g., Lewis, Butterfield, Darbes, \& Johnston-Brooks, 2004). These couples also reported some tactics work better than others (Lewis et al., 2004; Tucker \& Mueller, 2000).

We must also explore the meanings patients and partners attribute to talk about lifestyle change. Studies of non-cardiac populations suggest that when a partner's encouragement is interpreted as positive or supportive it is more likely to promote healthful behavior, whereas a partner's attempts that are interpreted as negative or controlling are associated with ignoring the partner, doing the opposite of a desired behavior change, and hiding unhealthful behaviors (Helgeson, Novak, Lepore \& Eton, 2004; Lewis \& Rook, 1999; Tucker \& Anders, 2001; Tucker \& Mueller, 2000). Franks and her colleagues (2006) examined partner social support, partner social control, and patient heart healthy behaviors during the first three months of a cardiac rehabilitation program and six months later. In the early time period, partner support and patient health behavior were positively associated but these early levels of support did not produce

This is an Accepted Manuscript of an article published by Taylor \& Francis Group in Journal of Applied Communication Research on November 25, 2011, available online: http://dx.doi.org/10.1080/00909882.2011.636373 
patient health behavior six months later. Partner control in the early months did predict patient health behavior six months later-and the association was a negative one.

In the present study, we use qualitative methods to describe the forms and meanings of talk about lifestyle change. This complements previous quantitative studies that have used broad tactical dimensions to differentiate effective and ineffective strategies (e.g., positive/negative, bilateral/unilateral, direct/indirect) and general dimensions of interpretation (e.g., supportive/controlling). Such dimensions, and the characterization of talk as “more or less” of those dimensions, are essential to quantification and prediction but they can be difficult for couples and practitioners to translate into specific changes in communication behavior. Our study describes specific discourse features that are linked to interpretations.

Our approach also represents a shift in the types of questions we ask about couple interaction. Rather than generalizing about the best way to communicate, we explore how patients and partners make sense of their interactions. Rather than presuming that behavior can be uniformly quantified in degrees of positive, bilateral, direct, or supportive, we believe communication is strategic action whose meaning arises in particular contexts. An important theoretical task is to understand the categories through which contexts are understood and actions are made meaningful. This task is also eminently practical. Few of us set out to be controlling, unilateral, and negative, particularly when we are communicating with a beloved partner about a life-threatening health condition; consequently advice to "be positive not negative" or "be supportive, not controlling” misses the point. Instead, we provide conceptual tools that enable couples to see how their interactions might be seen as "controlling" and what alternative actions and interpretations are possible. Elsewhere, this approach has been

This is an Accepted Manuscript of an article published by Taylor \& Francis Group in Journal of Applied Communication Research on November 25, 2011, available online: http://dx.doi.org/10.1080/00909882.2011.636373 
characterized as normative (Goldsmith, 2001; Goldsmith \& Fitch, 1997), rhetorical (Goldsmith, 2004), rational (O’Keefe, 1992), or practical (Tracy, 2008).

Goldsmith’s (2004) theory of communicating social support provided a theoretical framework for our investigation. Goldsmith proposes that the meanings partners attribute to their talk are a central link between their communication and desired outcomes such as lifestyle changes. The model focuses on patterns of behavior and meanings that are common to particular kinds of situations in a particular socio-cultural group. Of central interest are meanings related to tasks conversationalists wish to accomplish and the valued identities and relational qualities that are expressed (or threatened) by going about a task in a particular way. Those situations that are most often of interest (to lay people and scholars alike) are those in which there is potential for multiple, conflicting meanings. So, for example, the communication task of a female partner encouraging a recovering male patient to let the neighbor shovel snow may be complicated by what the conversation implies about both parties’ identities (e.g., Is he still masculine? Is she a nag?) and about their relationship (e.g., Does she think she knows better than he does what he can and can’t do? Is he insensitive to her worries?). Whether or not participants are able to accomplish a task with desirable identity and relational interpretations explains why conversations are evaluated positively or negatively. A description of meaning management strategies provides practical insight into a particular problem area and also refines our understanding of more general communication processes, including how relational partners give social support, gain compliance, enact identities and construct relationships.

The present study is the third in a series. Our first study (Goldsmith, Gumminger \& Bute, 2006) described how patients and partners talk. We developed conceptual categories that

This is an Accepted Manuscript of an article published by Taylor \& Francis Group in Journal of Applied Communication Research on November 25, 2011, available online: http://dx.doi.org/10.1080/00909882.2011.636373 
captured variability in the form of talk, including frequency, speech event, and style. Some couples engaged in unrestrained talk about lifestyle change, some talked infrequently, and some took care to be selective about when they talked or how much they said. Talking about lifestyle change also differed depending on the type of speech event in which it occurred. For example, arguing about changes is much different than praising a patient's efforts or engaging in problemsolving discussions together. Finally, the style of talk varied. Some patients or partners were very direct, whereas others used inquiries, suggestions, joking, or nonverbal communication to make a point.

Our second study (Goldsmith, Lindholm, \& Bute, 2006) developed conceptual categories to capture how patients and partners interpret their talk about lifestyle change. We found talking about lifestyle change could mean caring, concern, and fulfilling one's role as a responsible partner; conversely, not talking could symbolize not caring about the patient's recovery. However, talk could also be heard as nagging, a term connoting criticism and threats to autonomy. Partners wished to fulfill their obligation to help while avoiding becoming “gatekeepers” who exercised undue control. Finally, talking about lifestyle change implicated identities as healthy or sick. Talking was a reminder that life had changed, and this might be seen as empowering patient and partner to take control of health or as a loss of pleasures and freedom.

Now that we have identified conceptual categories of form and meaning, we wish to develop a model of their linkages. The present study explores how different ways of communicating can be adaptive to the dilemmas that arise from the multiple possible meanings of couple talk. Whereas our previous work identified forms of talk, here, we explore the advantages and disadvantages of those forms to interpretations of talk as caring, concerned,

This is an Accepted Manuscript of an article published by Taylor \& Francis Group in Journal of Applied Communication Research on November 25, 2011, available online: http://dx.doi.org/10.1080/00909882.2011.636373 
critical, disempowering, and so on. Our analysis also revealed the ways in which an individual's interpretation of talk is contextualized by efforts to frame interaction and by the use of environmental resources.

\section{Methods}

We conducted qualitative interviews with individual patients and partners. Many interactions about lifestyle change occur spontaneously in private as part of the rhythms of everyday life. Interviews gave us self-reports of these interactions as well as the partners' interpretations; interviewing patients and partners separately enabled them to be frank about relational dynamics. Because we wished to expand the categories used to understand talk beyond dichotomous continua, we employed interpretive methods to develop categories inductively rather than coding for previously identified dimensions.

Participants were 25 patients who had MI $(n=6)$, CABG $(n=8)$, or both $(n=11)$ in the last year; 15 partners of these same patients; and one partner of a patient who did not participate in the study. We did not insist that both members of a couple participate because this could skew our sample toward a particular kind of couple (e.g., those in which both members valued communication, those who like to do things together). We recruited participants through flyers in cardiologists’ offices, announcements at support group meetings and cardiac rehabilitation classes, posters in churches, and referral by other study participants.

The mean age of participants was $64.78(S D=10.99$, range $=37$ to 81$)$. Our sample was predominantly of European American descent. Our participants reported a wide variety of present and pre-retirement occupations in government, ministry, industry, agriculture, medicine, trades, home-making, and small business. Among our participants, 29.3\% had a high school

This is an Accepted Manuscript of an article published by Taylor \& Francis Group in Journal of Applied Communication Research on November 25, 2011, available online: http://dx.doi.org/10.1080/00909882.2011.636373 
degree, $26.8 \%$ had completed some college, $17.1 \%$ held a college degree, and $28.8 \%$ held graduate or post-graduate degrees. All partners were women, four patients were women, and all couples were opposite-sex relationships (40 marriages, 1 committed romantic partnership). The average length of relationship was 36.09 years $(S D=16.08$, range $=3$ to 55 years). Four participants had children under age 18 living with them and 36 had grown children.

We acknowledge limitations to our sample. Although we solicited participants through several channels, rehabilitation classes were our most effective recruitment site. This may overrepresent patients who had made lifestyle changes, though we found talking can be difficult even for those who have had some success in making changes. Our sample is racially homogeneous and relationally satisfied. The small number of female patients and the absence of male partners or same-sex couples in our sample limit our ability to pursue gender comparisons.

Participants engaged in a 60 to 90 minute semi-structured interview. We started with open-ended questions about changes they had experienced since the patient's cardiac event. Then, we asked what topics were easy to discuss, difficult to discuss, and sources of argument. This allowed us to discover salient issues before asking how they talked about a list of common challenges research has shown to be associated with recovery from a cardiac incident, including: adherence to diet, physical limitations, concerns about recurrence, changes in roles, sex, talking to others outside the primary relationship, and depression. Throughout the interview, we probed for examples of particular conversations and near the end, we asked interviewees to describe one good conversation about the heart condition and one conversation that had not gone well or that they wished they could do over. These questions are a variation on the critical incident interview and were used to reveal criteria participants used to evaluate communication. We concluded the

This is an Accepted Manuscript of an article published by Taylor \& Francis Group in Journal of Applied Communication Research on November 25, 2011, available online: http://dx.doi.org/10.1080/00909882.2011.636373 
interview by asking for advice to other couples; this revealed participant beliefs about effective ways of coping and communicating. Interviews were transcribed verbatim.

Previously, we had developed typologies of forms and meanings of talk about lifestyle change. In this study, our guiding analytic questions linked these previously developed concepts, asking: "How do individuals and couples manage meaning when they talk about lifestyle change? How are features of their communication linked to the meanings they derive?” We used constant comparison and theoretical comparison (Strauss \& Corbin, 1998) to look for common themes in participants’ own statements about what did and did not work for them (e.g., several partners said it was stressful to refrain from commenting) and also to notice patterns that emerged by contrasting one strategy with other possibilities (e.g., What are some ways joking differs from problem-solving?).

\section{$\underline{\text { Findings }}$}

All of the patients had undertaken one or more lifestyle changes in response to the cardiac event and had talked with their partner at least once about these changes. Participants varied in the meanings they attributed to their talk and in their satisfaction with those meanings. We identified three general classes of strategies patients and partners used to construct positive meaning and cope with the potential for conflicting meanings: communicative strategies, interpretive lenses, and environmental resources.

\section{$\underline{\text { Communication Strategies }}$}

We found several ways participants used the frequency, style, and speech event framing of talk to deal with threats to identity and relationship. Table 1 gives a brief summary of these strategies, their advantages and disadvantages for managing meanings, and when they seemed to

This is an Accepted Manuscript of an article published by Taylor \& Francis Group in Journal of Applied Communication Research on November 25, 2011, available online: http://dx.doi.org/10.1080/00909882.2011.636373 
work best.

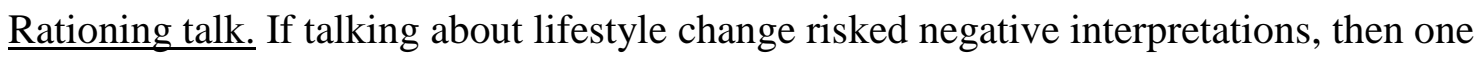
way to reduce risk was to reduce the amount of talk. Both patients and partners reported being selective about when or what facets of lifestyle change to discuss. For example, Simon ${ }^{1}$ reported that he and his wife talked frequently about menus and how to prepare foods but that she refused to nag him if he ate something he should not eat. Partners also moderated how often they talked about lifestyle change by saying it once. Patrick and his wife had a single conversation concerning his pipe smoking. His wife wanted him to give it up completely, and he agreed to smoke outside. Patrick valued the acceptance of his decision she conveyed by not bringing it up again. Partners also reported letting patients initiate talk about lifestyle change. Linda said of her husband’s struggle to quit smoking: “I don’t bring things up, you know. I let him approach me with it if he wants to talk about it.” Partners described going along with a patient's occasional violation and deciding whether or not to comment on behavior by assessing the patient's overall compliance and whether the occasion was exceptional in some way. Joyce supported her husband's dietary changes by talking enthusiastically about healthful menu options when they ate out and keeping forbidden foods out of the house. But she also pointed out, "Life’s short, you have to have a few enjoyments, and if you can get some jollies from a candy bar, let him have them.” A similar judgment process was reflected in the comments of partners who monitored some threshold, withholding comment up to a point and then determining to say something. Roger reported that he was allowed two or three eggs a week and that his wife would willingly fix them for him but that beyond that, "she'll yell and holler."

Rationing talk entails alternating talk with restraint. It shows caring and respect for one’s

This is an Accepted Manuscript of an article published by Taylor \& Francis Group in Journal of Applied Communication Research on November 25, 2011, available online: http://dx.doi.org/10.1080/00909882.2011.636373 
own and the other's identity and recognizes the limits on one person's control over the other. While some couples were satisfied with this way of balancing risk and benefit, it did sometimes create stress, particularly for partners. Withholding comment, waiting for the patient to bring it up, or waiting until violations became extreme could miss opportunities for problem-solving together. For rationing talk to be seen as respectful and caring rather than uninvolved, patients must see that the failure to comment on unhealthful behaviors is due to restraint, and not lack of interest. Several of our respondents who used rationing successfully had at some point told the other person this was what they were doing.

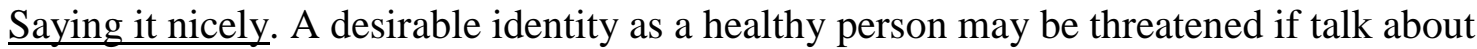
lifestyle change is taken as a reminder of the patient's sick role or failure to live life fully. Several undesired meanings of lifestyle change talk also resemble what Brown and Levinson (1987) call threats to face (i.e., criticism threatens positive face, control threatens negative face). Not surprisingly, then, partners modified the style of their speech in face-saving ways-a strategy some called, “saying it nicely.” If some of the meanings of talk are not-so-nice, then saying it nicely can compensate or can emphasize positive meanings of caring and relational responsibility.

Our respondents gave many examples of using conventional indirectness (Brown \& Levinson, 1987) to comment on lifestyle issues. When a patient was doing or eating something off-limits, a partner made a statement that they both knew meant “don't do that” but did not literally say so (e.g., “It’s not good for you” means “you shouldn’t do it”). When Rita saw her husband preparing fried bologna and onions, she knew for certain that this was not part of a heart-healthy diet, but she expressed concern by saying, "I wonder if you should be doing that."

This is an Accepted Manuscript of an article published by Taylor \& Francis Group in Journal of Applied Communication Research on November 25, 2011, available online: http://dx.doi.org/10.1080/00909882.2011.636373 
Similarly, nonverbal communication could enable one person to infer the other's intent without words. Several patients and partners described "the look" that communicated disapproval of a dietary infraction or concern about overdoing activities.

Inquiries and suggestions could be indirect ways of directing a patient's behavior. Partners expressed concerns in the form of questions, to which patients usually replied with reassurance. After these brief interactions, the partner did not persist in talking about the issue even though he or she might still be worried. ${ }^{2}$ For example, Kirby told how his wife would say, “'Should you be doing that? Honey, don't hurt yourself.' You know, that kind of reaction. And I tell her, I say, 'I'm fine. I've got to try.' . . . She still worries.” Partners also phrased alternative actions as suggestions rather than directives.

Routinized exchanges occurred repeatedly and rather than changing behavior, they symbolized relational caring and responsibility. These verbal rituals re-occurred within a given couple, and there were strong resemblances among the exchanges reported by different couples. For example, in situations in which Simon might be tempted to overexert, he said his wife routinely said, “Now you're not going to do that, are you?” to which he replied, “No,” followed by her saying “You promise?” He did not mid the ritual because it showed she cared and he appreciated that after a brief exchange she did not say any more. Repetition can make a patient feel nagged but routinized exchanges had a shared interpretation as ritual expressions of concern, rather than annoying repeated attempts to alter behavior.

Some patients and partners reported joking about lifestyle changes. George laughingly reported how his wife tells him “if you eat that, you'll die and it's your own fault” and how, in turn, he "tormented" her by saying he was going to do something unhealthful when they both 
knew he wasn't going to do it. There is truth in what George's wife says about diet as a risk factor but exaggeration allows her to make her point in a vein that cannot quite be taken seriously. George's teasing reply plays the role of an independent man who ignores his wife even as he complies with her and with his regimen. The potential tension arising from reminders that one person is ill and the other is not could be finessed with good humor that emphasized their common relational bond (cf. Hilscher, Bartley, \& Zarski, 2005).

Partners and patients observed that various methods of saying it nicely allowed partners to comment on lifestyle change without "getting on” or "nagging” the patient. These strategies often involved a sequence of questions and answers - a pattern that gives the patient some authority over his or her choices. Saying it nicely affirms closeness, mitigates power differences, and avoids treating the patient like an invalid. Yet these strategies also have limitations. Whereas speaking directly makes intentions quite clear, patients (or partners) can miss the point of an indirect call to healthful behavior, either intentionally or inadvertently. This could place the speaker in a conversational dilemma: to continue talk about the topic requires not only correcting health behavior but disambiguating communication behavior. For example, if a partner asks, "Is it OK to do that?” and the patient says, “Yes,” the partner may still not be reassured but may have difficulty pursuing the topic further without implying the patient has poor judgment. A pattern of indirect communication could also lead patients to infer disapproval or concern when partners do not intend it. Likewise, being indirect can require extra interpretive work of the hearer or suggest an issue is more sensitive than it ought to be. Thus, these indirect strategies seemed to work best when patients were basically following a heart-healthy lifestyle and when both patient and partner shared interpretation of the indirect strategy. Absent these conditions,

This is an Accepted Manuscript of an article published by Taylor \& Francis Group in Journal of Applied Communication Research on November 25, 2011, available online: http://dx.doi.org/10.1080/00909882.2011.636373 
indirect strategies could be a source of building frustration or resentment.

Framing it cooperatively. Discursive reframing constructs a new definition of the communication situation so that talking about lifestyle change no longer threatens valued identities or relational definitions (cf. O’Keefe, 1990). Features such as who raises a topic, how they word things, and what the other says in response produce the difference between a partner telling a hapless patient what to do versus a partner giving support for the patient's problem versus patient and partner working together on a shared challenge.

In problem-solving discussions couples worked together to determine how to make a change or resist temptation. These discussions usually occurred when the patient recognized the importance of lifestyle change and focused on how to achieve it in a particular set of circumstances. Numerous respondents used "we” and "our” to describe lifestyle changes as jointly undertaken challenges. In conversations framed as "giving social support” or "seeking compliance," one partner tries to help or influence the other. In contrast, partners work together in a problem-solving discussion. This side-steps the implications that one person is trying to control or criticize the other, that one person is well and the other is ill, or that either person is leading a diminished life. However, partners who become highly invested in the patient’s lifestyle change may experience stress if patients are unable to make those changes or experience health setbacks despite their best efforts (Coyne, Wortman, \& Lehman, 1988). In those circumstances, partner involvement may produce resentment, criticism, or overprotection and spark patient resistance and defensiveness.

Some couples reported meta-communication: engaging in problem-solving discussion about their talk. For example, Carl told his wife he found it irritating when she expressed concern

This is an Accepted Manuscript of an article published by Taylor \& Francis Group in Journal of Applied Communication Research on November 25, 2011, available online: http://dx.doi.org/10.1080/00909882.2011.636373 
that he was “overdoing." She explained that her ongoing comments of “don’t do that” and "be careful” came from her own fears and he said he would abide by the limits his physician recommended. Some interventions encourage couples to meta-communicate about their preferences (e.g., “Do you want me to comment when you go off your diet?”) and their interpretations of one another’s actions (e.g., "I feel like a child when you tell me what to do”). This is a potentially powerful strategy that recognizes multiple meanings of talk, validates communication challenges couples face, and provides a way to see one another's otherwise annoying behavior in a more charitable light. However, meta-communication was rare among our couples (a pattern also observed in relationships more generally, see Wilmot, 1980). If metacommunication is infrequent, then recommending that couples do it could amount to just one more lifestyle change they are asked to make during a stressful time. Meta-communication can also be threatening if it involves questioning one’s own or the other’s motives and acknowledging that life is not the same (i.e., we never had to talk about our communication before). Of the few couples in our sample who reported meta-communication, some did it naturally and with good results while for others, it was just one more source of argument. Consequently, clinicians who recommend meta-communication may also need to provide guidance in doing it (e.g., Sher \& Baucom, 2001).

Frames such as problem-solving discussion or meta-communication manage dilemmas by placing respondents in symmetrical roles to solve a shared problem. Another constructive frame for talk occurred when patient and partner were cast as agreeing rather than arguing with one another. Our respondents reported brief but direct acknowledgments of a desire for something that was unhealthful. For example, Georgia reported that when her husband said how food tastes

This is an Accepted Manuscript of an article published by Taylor \& Francis Group in Journal of Applied Communication Research on November 25, 2011, available online: http://dx.doi.org/10.1080/00909882.2011.636373 
better with salt, she agreed. Although talking about patient motives and frustrations might be undertaken with the goal of attempting to challenge or change them, there was also great power in simply voicing feelings of loss, restriction, or deprivation. At the same time, if only loss is acknowledged, this may undermine motivation to engage in change.

Another frame that foregrounds agreement is praise for a patient's change. Paul said his wife "tells me how much better I look from losing weight" and brags to others about how he sticks to his diet. Praise implies evaluation and in our data, a partner's positive evaluations were affirming; however, we can imagine the possibility that praising a patient could make the partner appear superior or condescending. We also found patients who praised their partners for their compassion and efforts to facilitate change. Just as Paul's wife praised him, he also said he appreciates her more now than before. He tells her, "hey thanks for doing that!” and praises her for losing weight on their shared diet. We suspect this reciprocity tilted the interpretation of praise toward affirmation of closeness and positive feeling rather than condescension.

Acknowledging and praising were not reported often but have the potential to be quite useful. When partners verbally acknowledged change was difficult and praised progress, this enabled them to play a supportive role rather than setting themselves up as adversaries or gatekeepers. When patients acknowledged or praised partner effort, it affirmed the legitimacy of partner involvement and created reciprocity. Being able to utilize these strategies presumes a patient wants to be compliant and that there is some lifestyle change occurring (otherwise praise risks complicity and acknowledgement emphasizes barriers to compliance). Partners with more recalcitrant patients or patients with uncooperative partners have fewer opportunities to exercise these strategies.

This is an Accepted Manuscript of an article published by Taylor \& Francis Group in Journal of Applied Communication Research on November 25, 2011, available online: http://dx.doi.org/10.1080/00909882.2011.636373 


\section{Contextualizing Communication: Interpretive Lenses and Environmental Resources}

We found communication strategies were closely intertwined with how couples chose to think about their interactions and what home routines and social network resources they had in place. This led us to develop two additional categories of strategies for managing meanings: interpretive lenses and environmental resources. The "same” communication strategy might be more or less plausible in the first place, or might receive a different reaction depending on these contextualizing strategies.

Interpretive Lenses. Participants who used interpretive lenses had adopted ways of decoding their talk that reduced threats to identity and relationship. These overarching mindsets helped them justify their own interaction choices, interpret one another's behavior, and cope with the challenges of communicating. For example, participants talked and made sense of their interaction in light of their relational history, which was lengthy for many of our couples. In addition, participants' comments revealed how a particular communication pattern worked (or did not work) for them within a specific set of attributions or beliefs.

Attributions of legitimacy--that the other person had a right or reason to say something-played a role in how patients and partners reacted. For example, George said of his wife’s reminders to avoid heavy lifting: “No, it doesn’t bother me. I figure that's her job.” Even her very direct statements were “fine” because “I know it’s best for me.” This interpretive lens took the edge off of what might otherwise have appeared to be directive behavior. Likewise, one person may acknowledge that the other knows what he or she is doing and can be trusted to make good choices without oversight.

Both patients and partners discussed the importance of patience. For example, time

This is an Accepted Manuscript of an article published by Taylor \& Francis Group in Journal of Applied Communication Research on November 25, 2011, available online: http://dx.doi.org/10.1080/00909882.2011.636373 
pressure to complete a task could lead a patient to overexert and a partner to feel compelled to comment. In contrast, if both were willing to complete a task slowly and with frequent rest breaks, it obviated the need to argue over who should do the task. Rita said she worried about her husband painting their bedroom early in his recovery, but she decided not to worry about how long it took him to finish. It took two weeks, but he completed the task without a word from her. Patience also applied to one another’s behavior. Linda observed that her husband became irritable when he was trying to quit smoking and found that she had to "let it roll off" and then he got back to "his old self."

Participants revealed a variety of ways they emphasized the positive when interpreting potentially problematic behaviors. For example, Carol attributed her husband's violations of his diet to simply forgetting, which also made her comments simple "reminders.” Emphasizing the positive also included focusing on the effort a patient or partner was making rather than times he or she fell short of the goal. For example, Donna gave her husband credit for trying to cut down portion sizes, saying: “[H]e grew up on the farm years ago when you ate big meals three times a day, meat three times a day...I think he’s really trying on that.” Emphasizing the positive makes it easier to find things to praise or to deal with infractions by saying it nicely or rationing talk.

Another lens involved viewing the task of talk about lifestyle change as encouraging moderation, balance, and gradual change (rather than total change or abstinence). Asked if her husband ever eats something he shouldn't, Faith answered that “he doesn’t do it to excess” and said she might comment “depending on what it was” and how much he ate. She saw her job as encouraging moderation, so she felt comfortable rationing talk or saying it nicely. In contrast, Ken and Rose felt moderation was a slippery slope to bad habits. Ken said, “[I]f you moderate

This is an Accepted Manuscript of an article published by Taylor \& Francis Group in Journal of Applied Communication Research on November 25, 2011, available online: http://dx.doi.org/10.1080/00909882.2011.636373 
just a little and then a little more, the first thing you know you're back to where you started from.” Rose confirmed that she is "very careful” about what they eat and said, "it really bothers me” if they eat very much that is not on their diet. For Ken and Rose, rationing talk or being too indirect would be stressful. Instead, they meta-communicated about her feeling responsible for their diet and about his reactions when she expressed concerns.

Believing that lifestyle changes are good for both people is related to a variety of communicative actions. For example, when both people changed diet and exercise, this was consistent with problem-solving discussions. A quite different example comes from Barbara’s communication with her husband, Matthew, who had CABG. She did not comment when he ate something he should not because, "I’m as bad too!. . . Yeah, it's bad for everybody. So that'd be the pot calling the kettle black.” Because Barbara recognizes she also needs to change her diet, it makes sense to her to refrain from comment; if Barbara had an exemplary diet or felt Matthew’s diet did not apply to her, she might feel more comfortable saying something to him.

Finally, the perception that the patient is generally compliant shaped reactions to conversations about lifestyle change. For example, Lisa described how her husband has eaten well, exercised, and gathered information. When he did eat something high fat she either refrained from comment or engaged in a routinized exchange. She acknowledged, "I was never tested...I know I would have been bad” about nagging him to eat well if she had not believed he was making healthful choices. Simon concurred that, "I didn’t get any nagging,” and said it’s “'cause I'm a good boy!”

\section{Environmental Resources}

This category involved utilizing resources external to the couples’ conversations about

This is an Accepted Manuscript of an article published by Taylor \& Francis Group in Journal of Applied Communication Research on November 25, 2011, available online: http://dx.doi.org/10.1080/00909882.2011.636373 
lifestyle change. Manipulating the context in which talk about change occurred could obviate the need for talk, create a more conducive setting for talk, or justify engaging or resisting talk. Daily life in a couple’s household and their communication with others in their social network were two types of environmental resources.

Using or changing household patterns. The meanings of lifestyle change talk were related to everyday events such as shopping, food preparation, recreation, home maintenance, ordinary talk, and shared activities. In some couples one or both members made prior arrangements to minimize temptations. Couples reported keeping unhealthful foods out of the house or changing which restaurants they patronized. By reducing the occasions for unhealthful behavior, participants reduced the need for discussing difficult decisions or pointing out unhealthful behavior.

Structuring the environment also included conscious efforts to make lifestyle changes attractive. For example, Larry reported how his wife would bring to a table where he was working a nicely arranged platter of fruits and vegetables. "She puts them down but she doesn’t say anything about 'you have to eat these.”’ The obvious effort she had made, the appealing presentation, and the ease of eating a healthful snack motivated him to eat well. His wife independently reported that she felt it was important to make healthful food delicious, attractive, and easily available. The need to cajole or comment upon lifestyle choices can be reduced if healthful choices have intrinsic appeal.

Some couples had begun making lifestyle changes prior to the cardiac event so that changes their physician recommended in the wake of the event were seen as part of a longer process. Carl described how he and his wife had gradually become nearly vegetarian over the

This is an Accepted Manuscript of an article published by Taylor \& Francis Group in Journal of Applied Communication Research on November 25, 2011, available online: http://dx.doi.org/10.1080/00909882.2011.636373 
past 15 years, so that changes did not require conversation but had become "just sort of a way of life.” Similarly, Ken and Rose had been “walkers” before his bypass surgery and so it seemed natural to continue to exercise together as he recovered. Talk about lifestyle changes did not stand out as a problematic event in need of interpretation or management because the changes had been gradual.

Our participants described how ordinary talk in the course of daily activities enabled them to coordinate lifestyle changes without explicit discussion (see also Goldsmith, 2004). Rita was leery of constantly reminding her husband of his heart condition and so she utilized everyday interactions to monitor his progress. Casual conversation over breakfast could touch on how he slept, what he planned to make for lunch, and what she planned to make for dinner. She felt their everyday talk gave her ways to support diet and activity changes without explicitly reminding him of his chronic illness and provided openings for him to initiate the topic if he desired it.

Shared activities could intersect with talk about lifestyle change in useful ways. Several couples walked together. In addition to valued companionship and support, walking with a patient in recovery also let partners observe for themselves how far a patient could walk without duress. Rather than asking, “Are you sure it’s all right?” or admonishing a patient, “Don’t over do!” partners who walked along could see that patients were exercising appropriately. Shared activities can also facilitate shared interpretations when couples do decide to talk about lifestyle changes (cf. Hong et al., 2005). Ray said he and his wife had both needed to make health-related changes to their diet. He said, "We don’t have any arguments over food or anything. We just ... go over our list, and we go down and buy what we need for the whole week.” Watching their

This is an Accepted Manuscript of an article published by Taylor \& Francis Group in Journal of Applied Communication Research on November 25, 2011, available online: http://dx.doi.org/10.1080/00909882.2011.636373 
diets was mutually understood to be "helping each other out" and had been integrated into their shopping and other daily routines.

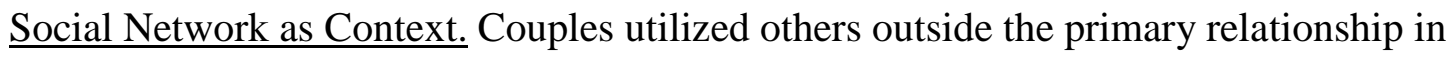
order to facilitate communication within their relationship. Patient and partner interactions with health care providers (e.g., cardiologists, primary care physicians, rehabilitation nurses, dieticians) affected a couple’s own conversations. For example, partners cited doctor’s orders when trying to persuade patients to make changes and patients used instructions from health care providers to defend dietary choices or new activities. Participants also used written and media sources of information. Rita reported, "It bothered me when I saw him buy a pound of butter. And he said. . . he saw something on television where they said it was just as good to eat the butter as the oil.” She relayed to him what her dietician said about fats and showed him information on the butter label. Written materials also provided a non-threatening way of introducing a sensitive topic, such as when to resume sexual activity.

A confidant outside the couple could influence how patients and partners talked with one another. Being able to talk about one's frustrations with someone other than the partner or to compare notes with someone else who had been through a similar experience helped patientpartner communication in several ways. For example, following her MI, Katherine was frustrated at her husband's lack of support for her dietary changes. She was able to cope by talking with her sister instead. Ray explained how comparing notes with other patients in recovery had helped him understand why his leg (where veins for his CABG had been removed) gave him more trouble than his chest. In turn, he reassured his wife by reporting his peers’ experiences.

In some instances, third parties actively intervened in the patient-partner dynamic. Lois

This is an Accepted Manuscript of an article published by Taylor \& Francis Group in Journal of Applied Communication Research on November 25, 2011, available online: http://dx.doi.org/10.1080/00909882.2011.636373 
reported that her husband and daughter were quite close and she described their interactions about his dietary changes: "She just outright tells him. I think he can take more from her than he does from me.” Even when third parties were no more effective than partners in bringing about behavior change, nonetheless their validation of the lifestyle change message influenced whether a partner was seen as an unreasonable nag, critic, or killjoy versus a concerned and responsible partner.

\section{$\underline{\text { Discussion }}$}

Following a cardiac event, patients who make lifestyle changes can improve recovery, enhance quality of life and prevent future cardiac events. Yet many patients find it difficult to adopt a heart-healthy diet, exercise, reduce stress, and stop smoking. Studies showing that partner support can encourage lifestyle change are the basis for interventions that involve partners, yet partner efforts may be interpreted as welcome support or as undesired control.

The present study began as a straightforward inquiry into communication strategies couples employ to manage meanings, the advantages and disadvantages of different forms, and the conditions under which each form was most successful. This way of thinking is familiar to communication scholars. It assumes that forms are strategic choices about how to achieve competing goals within a situation defined by pre-existing factors that affect how one assesses the strategy. Our analysis led us to alter this strategy-centric focus. We found that communication strategies were contextualized by other strategies, including interpretive lenses and environmental resources, and that there is a dynamic relationship among communication, interpretation, and environment. Uncovering patterns of communication, lenses, and resources in particular couples explains their varying experiences talking about lifestyle change.

This is an Accepted Manuscript of an article published by Taylor \& Francis Group in Journal of Applied Communication Research on November 25, 2011, available online: http://dx.doi.org/10.1080/00909882.2011.636373 
Our findings complicate the too-simple advice that couples just need to communicate about lifestyle change, or that partners should be supportive not controlling. There are many strategies for talking about lifestyle change that reinforce closeness, caring, responsibility, and empowerment while avoiding or minimizing connotations of criticism, control, sickness, and loss. Patients and partners can ration risky talk by being selective about topics, saying something once, letting the patient initiate discussions, going along with occasional violations, or monitoring a threshold of unhealthful behavior before commenting. Patients and partners can “say it nicely” by using conventional indirectness, inquiries and suggestions, routine exchanges, joking, and nonverbal cues. Finally, couples can frame talk about lifestyle changes cooperatively through joint problem-solving discussion or meta-communication and they can highlight agreement by engaging in acknowledgement of desires for unhealthful options or praise for healthful choices.

Each of these strategies had both advantages and disadvantages, underscoring the need to encourage couples to explore their options rather than giving one-size-fits-all advice about communication. Too often, recommendations to couples (e.g., American Heart Association, 2011) and to health care professionals who work with couples (e.g., Moser, 1994; Rolland, 1994) are based on a therapeutic model that advocates more talk or more open talk or more metacommunication. These are viable options but they are not the only or most natural ways for couples to discuss lifestyle change. Some couples may need to talk more openly about their intentions, but some couples may find it helps to ration talk. Further, if couples are having difficulty changing health-related behaviors, we should be cautious about adding prescriptions for changing communication behaviors, too.

This is an Accepted Manuscript of an article published by Taylor \& Francis Group in Journal of Applied Communication Research on November 25, 2011, available online: http://dx.doi.org/10.1080/00909882.2011.636373 
Variations in interpretive lenses and environmental resources also complicate advice about how to talk. Couples adopt varying ideas about the legitimacy of one another's comments, the appropriate amount of patience, how much to emphasize the positive, whether moderation is their goal, whether both people need to make changes, and whether the patient is compliant most of the time. Their home environments differ, including how many temptations patients face, how attractive changes are, whether changes had already started prior to the cardiac event, and whether ordinary talk and shared activities afford opportunities to facilitate change. The social network environment provides different access to health care providers or confidants and interventions by third parties. These interpretive lenses and environmental resources contextualize how patients and partners interpret their communication, shaping what they see as plausible strategies and how they react to strategies. A variety of configurations might produce patient lifestyle change in a way that is individually and relationally satisfying (and, conversely, a communication strategy that works for one couple might be ineffective for another couple with different interpretive lenses and environmental resources). Some couples will find it helpful to adopt new ways of talking but other couples might benefit from reinterpreting existing patterns of communication, changing household routines, or talking to someone other than, or in addition to, their partner.

Instead of training couples in a single set of communication skills or strategies, we feel couples will benefit from becoming aware of what they are doing, considering alternative patterns and interpretations, and accessing environmental resources. Health care professionals who provide advice about lifestyle change might also facilitate reflection on communication, interpretive lenses and environmental resources. Interventions that involve partners could use our

This is an Accepted Manuscript of an article published by Taylor \& Francis Group in Journal of Applied Communication Research on November 25, 2011, available online: http://dx.doi.org/10.1080/00909882.2011.636373 
conceptual frameworks to describe a couple’s current circumstance, identify where they may want help or change, and suggest a range of alternatives. For example, highly directive social control attempts could reflect a lack of integration of lifestyle changes into daily life. Without daily routines and external social network pressure to reinforce lifestyle change, partners may feel forced to resort to stronger verbal tactics. We found that when patients and partners worked as a team to change their home environment and daily routines, this was a conducive framing for communication. It may also have created environmental supports that lessened the need for explicit social control attempts.

Parallels between our findings and the principles and practices of motivational interviewing (e.g., Miller \& Rollnick, 2002) point to directions for further research and application. Motivational interviewing addresses a client’s ambivalence about change and prompts the client to say things that facilitate change, such as articulating disadvantages of the status quo, advantages of change, optimism for change, and intention to change. The approach emphasizes honoring the client's perspective and affirming her or his capacity for change. Some of the partner strategies we identified resemble motivational interviewing techniques. For example, praising success, emphasizing the positive, and making change attractive directed talk toward reasons for change. Likewise, inquiries and routine exchanges prompted the patient to verbally affirm his intention to change. These similarities suggest an explanation for how these strategies may work.

Motivational interviewing can also help couples to identify interaction patterns that maintain problematic behaviors and to explore alternatives. For couples who desire therapy, motivational interviewing is one of several models ${ }^{3}$ that can facilitate insight into couple

This is an Accepted Manuscript of an article published by Taylor \& Francis Group in Journal of Applied Communication Research on November 25, 2011, available online: http://dx.doi.org/10.1080/00909882.2011.636373 
communication. Motivational interviewing also has potential for couples who are not interested in therapy. It has been adapted for use by health care professionals and has shown some success in supporting lifestyle change and treatment adherence (Miller \& Rollnick, 2002). The ability to adapt techniques of motivational interviewing for use by health care professionals and in patient education settings suggests this may be a flexible and evidence-based therapeutic framework within which to implement our descriptive findings.

The significance of our findings extends beyond the particular concerns of couples coping with a cardiac event to include broader implications as well. Our findings shed light on the ongoing scholarly dialogue about the mechanisms through which social relationships affect health outcomes (e.g., Cohen, Gottlieb, \& Underwood, 2000). Some theorists have emphasized social support while others have focused on social control. Our findings reveal how closely support and control are intertwined (cf. LePoire, Hallett, \& Erlandson, 2000). A conversation about some life stressor may be interpreted as support, control, or both and more. Support and control have usually been studied as separate phenomena, missing opportunities to see their joint influence and to see how participants’ own efforts to present their talk as one or the other shapes their success in meeting their goals. Likewise, interventions to increase partner support rarely consider how these efforts might be experienced as control. Previous theory and practice have too often presumed there are two ways to talk about lifestyle change: support behaviors, which have positive effects and are recommended, and control behaviors, which have negative effects and are discouraged. Instead, we uncovered multiple meanings of talk about lifestyle change that are shaped by communication strategies, interpretive lenses, and environmental resources.

Our study is strong in conceptualizing how patients and partners reach positive or

This is an Accepted Manuscript of an article published by Taylor \& Francis Group in Journal of Applied Communication Research on November 25, 2011, available online: http://dx.doi.org/10.1080/00909882.2011.636373 
negative interpretations of talk about lifestyle change but we do not predict quantifiable effects on behavior change. That would require measuring communication strategies, interpretive lenses, environmental resources, and meanings across all couples and linking these to appropriate measures of behavior change (ideally, in a longitudinal design). Although our findings could be used as precursors to such predictive work, we caution against simplistic models that presume communication strategies are the same across "levels" of interpretive or environmental variables or that interpretive and environmental factors are stable, pre-existing variables that moderate the effects of communication. Communication, interpretation, and environment can each be used strategically and each can serve as context for understanding how the other shapes meaning.

When we asked, “How do couples manage dilemmas of talk about lifestyle change?” “communication strategies” was not the only answer. Others have observed that cognitive processes intersect with communication strategies to predict satisfaction (cf. Caughlin \& Golish, 2002) and that the larger social network impacts couple communication (cf. Parks, 2007). Yet, these factors have seldom been treated alongside communication strategies as ways of responding to conflicting goals or conversational dilemmas. The conceptual model in Figure 1 shows how communication strategies, interpretive lenses, and environmental resources intersect in managing challenging communication situations. Each set of arrows in the model suggests refinements to the theory of strategic communication (Goldsmith’s 2004 model of supportive communication) that framed our study. ${ }^{4}$

First, what strategies seem like plausible responses to a dilemma may differ, depending on patient and partner interpretive lenses and environmental resources (the arrows on the left). Imagine a partner who perceives the patient as noncompliant, believes the goal of talk is $100 \%$

This is an Accepted Manuscript of an article published by Taylor \& Francis Group in Journal of Applied Communication Research on November 25, 2011, available online: http://dx.doi.org/10.1080/00909882.2011.636373 
abstinence, and has no opportunity to check these perceptions with a health care provider. Praise for the patient will be hard to come by and rationing talk may appear irresponsible. It is tempting to assume that couples start on a level playing field and that their playbook includes all the same strategic moves. In this view, a partner who nags simply needs to be informed of a better strategy. But “communication strategies” may not be as freely chosen as the term implies. Rather than actions selected to manage a situation, they may be responses to it; rather than choices we make from a menu, they may be the options left open to us by our situation (and our perception of it).

Second, when people interpret strategies in response to dilemmas, they utilize not only verbal and nonverbal cues, but also interpretive lenses and environmental resources (the arrows on the right). For example, those who interpret behavior through roles that legitimate talk and who see changes as something both people need to make are less likely to even consider that comments about lifestyle are nagging or overprotection. Conversely, those determined that their lifestyle is no one's business but their own will interpret negatively most attempts at talk, even those that are strategically in tune with communicative dilemmas. Environmental resources could give some couples a leg up on talking about lifestyle change (e.g., satisfactory information from health care providers, a history of shared exercise and activities, changes underway before the cardiac event, and confidants to check perceptions and assist in persuasion). If we test the efficacy of communication strategies across couples, or develop an intervention that recommends particular strategies to all couples, we might assume that the strategies are the same (or use a methodology that will make them so); yet "the same” strategy may look quite different, depending on the context.

This is an Accepted Manuscript of an article published by Taylor \& Francis Group in Journal of Applied Communication Research on November 25, 2011, available online: http://dx.doi.org/10.1080/00909882.2011.636373 
Third, some communication strategies may work by altering the interpretive lenses and environmental resources that contextualize future interactions (the use of double arrows). For example, meta-communication with one’s partner can alter perceptions of legitimacy and problem-solving conversations can change household routines. Relationships between communication and context are dynamic. Interpretive lenses and environmental resources are not simply stable factors that predispose actors to adopt one communicative strategy or another. Participants were sometimes quite intentional in their use of these contextual resources; and patterns of communication, interpretive lenses, and environmental resources can evolve (or devolve) together over time.

We do not wish to minimize the importance of strategic communication in response to dilemmas. Nor do we wish to discourage interventions in which communication is central. Rather, we wish to call attention to the ways that communication strategies and dilemmas are situated in individual and relational history and sense-making, in social networks, and in everyday life. The model we have proposed suggests another direction for future research and practice, not only with respect to couples coping with a cardiac event, but also in terms of strategic communication more generally.

Lifestyle changes are difficult for many patients who have experienced a cardiac event and for partners who wish to encourage them. Talking about lifestyle change can also be challenging. Our findings show how multiple meanings can be managed in talk and suggest that we attend to the ways communicative strategies intersect with interpretive frames and the social environment. Our descriptions may also directly impact couples and those who counsel them by validating the dilemmas of talking about lifestyle change and by facilitating reflection on a range

This is an Accepted Manuscript of an article published by Taylor \& Francis Group in Journal of Applied Communication Research on November 25, 2011, available online: http://dx.doi.org/10.1080/00909882.2011.636373 
of ways to meet those challenges.

\section{References}

American Heart Association (2011). General communication tips. In Caregiver reach out introduction. Retrieved from http://www.heart.org/HEARTORG/Caregiver/ ReachOut/ReachOutIntroduction/Reach-Out-Introduction_UCM_301840_Article.jsp

Brown, P., \& Levinson, S. C. (1987). Politeness: Some universals in language usage. Cambridge: Cambridge University Press.

Burke, L. E., Dunbar-Jacob, J. M. \& Hill, M. N. (1997). Compliance with cardiovascular disease prevention strategies: A review of the research. Annals of Behavioral Medicine, 19, 239263.

Caughlin, J. P., \& Golish, T. D. (2002). An analysis of the association between topic avoidance and dissatisfaction: Comparing perceptual and interpersonal explanations. Communication Monographs, 69, 275-295.

Cohen, S., Gottlielb, B. H., \& Underwood, L. G. (2000). Social relationships and health. In S. Cohen, L. G. Underwood, \& B. H. Gottlieb (Eds.), Social support measurement and intervention: A guide for health and social scientists (pp. 3-25). New York: Oxford University Press.

Cohen, S. \& Lichtenstein, E. (1990). Partner behaviors that support quitting smoking. Journal of Consulting and Clinical Psychology, 58, 304-309.

Coyne, J. C., Ellard, J. H., \& Smith, D. (1990). Social support, interdependence, and the dilemmas of helping. In B. R. Sarason, I. G. Sarason \& G. R. Pierce (Eds.), Social support: An interactional view (pp. 129-149). New York: Wiley.

This is an Accepted Manuscript of an article published by Taylor \& Francis Group in Journal of Applied Communication Research on November 25, 2011, available online: http://dx.doi.org/10.1080/00909882.2011.636373 
Coyne, J. C., Wortman, C. B., \& Lehman, D. R. (1988). The other side of support: Emotional overinvolvement and miscarried helping. In B. H. Gottlieb (Eds.), Marshalling social support: Formats, processes and effects (pp. 305-330). Newbury Park, CA: Sage.

Daly, J., Sindone, A. P., Thompson, D. R., Hancock, K., Chang, E., \& Davidson, P. (2002). Barriers to participation in and adherence to cardiac rehabilitation programs: A critical review of the literature. Progress in Cardiovascular Nursing, 17, 8-17.

Ell, K., \& Dunkel-Schetter, C. (1994). Social support and adjustment to myocardial infarction, angioplasty, and coronary artery bypass surgery. In S. A. Shumaker \&S. M. Czajkowski (Eds.), Social support and cardiovascular disease (pp. 301-332). New York: Plenum Press.

Franks, M. M., Stephens, M. A. P., Rook, K. S., Franklin, B. A., Keteyian, S. J., \& Artinian, N. T. (2006). Spouses provision of health-related support and control to patients participating in cardiac rehabilitation. Journal of Family Psychology, 20, 311-318.

Goldsmith, D. J. (2001). A normative approach to the study of uncertainty and communication. Journal of Communication, 51, 514-533.

Goldsmith, D. J. (2004). Communicating social support. Cambridge: Cambridge University Press.

Goldsmith, D. J., \& Fitch, K. L. (1997). The normative context of advice as social support. Human Communication Research, 23, 454-476.

Goldsmith, D. J., Gumminger, K. A. L., \& Bute, J. J. (2006). Couple communication and recovery from a cardiac event. In B. LePoire \& R. M. Dailey (Eds.). Socially meaningful applied research in interpersonal communication (pp. 95-118). New York: Peter Lang.

This is an Accepted Manuscript of an article published by Taylor \& Francis Group in Journal of Applied Communication Research on November 25, 2011, available online: http://dx.doi.org/10.1080/00909882.2011.636373 
Goldsmith, D. J., Lindholm, K. A., \& Bute, J. J. (2006). Dilemmas of talking about lifestyle changes among couples coping with a cardiac event. Social Science \& Medicine, 63, 2079-2090.

Haynes, R. B. (2001). Improving patient adherence: State of the art, with a special focus on medicaiton taking for cardiovascular disorders. In L. E. Burke \& I. S. Ockene (Eds.) Compliance in healthcare and research (pp. 3-21). Armonk, NY: Futura Publishing Company.

Helgeson, V. S., Novak, S. A., Lepore, S. J., \& Eton, D. T. (2004). Spouse social control efforts: Relations to health behavior and well-being among men with prostate cancer. Journal of Social and Personal Relationships, 21, 53-68.

Hilscher, R. L., Bartley, A. G., \& Zarski, J. J. (2005). "A heart does not beat alone”: Coronary heart disease through a family systems lens. Families, Systems, \& Health, 23, 220-235.

Hong, T. B., Franks, M. M., Gonzalez, R., Keteyian, S. J., Franklin, B. A., \& Artinian, N. T. (2005). A dyadic investigation of exercise support between cardiac patients and their spouses. Health Psychology, 24, 430-434.

LePoire, B. A., Hallett, J. S., \& Erlandson, K. T. (2000). An initial test of inconsistent nurturing as control theory: How partners of drug abusers assist their partners’ sobriety. Human Communication Research, 26, 432-457.

Lewis, M. A., Butterfield, R. M., Darbes, L. A., \& Johnston-Brooks, C. (2004). The conceptualization and assessment of health-related social control. Journal of Social and Personal Relationships, 21, 669-687.

Lewis, M. A., \& Rook, K. A. (1999). Social control in personal relationships: Impact on health

This is an Accepted Manuscript of an article published by Taylor \& Francis Group in Journal of Applied Communication Research on November 25, 2011, available online: http://dx.doi.org/10.1080/00909882.2011.636373 
behaviors and psychological distress. Health Psychology, 18, 63-71.

McMahon, M., Miller, P., Wikoff, R., Garrett, M. J., \& Ringel, K. (1986). Life situations, health beliefs, and medical regimen adherence of patients with myocardial infarction. Heart and Lung, 15, 82-86.

Miller, N. H., Hill, M., Kottke, T., \& Ockene, I. A. (1997). The multilevel compliance challenge: Recommendations for a call to action. Circulation, 95, 1085-1090.

Miller, N. H., Taylor, C. B., Davidson, D. M., Hill, M. N., \& Krantz, D. S. (1990). The efficacy of risk factor intervention and psychosocial aspects of cardiac rehabilitation. Journal of Cardiopulmonary Rehabilitation 10, 198-209.

Miller, P., McMahon, M., Ringel, K., Siniscalchi, K., \& Welsh, N. (1989). Personal adjustments and regimen compliance 1 year after myocardial infarction. Heart \& Lung, 18, 339-345.

Miller, W. R., \& Rollnick, S. (2002). Motivational interviewing: Preparing people for change, 2ed.. New York: Guilford.

Moser, D. K. (1994). Social support and cardiac recovery. Journal of Cardiovascular Nursing, 9, 27-36.

O’Keefe, B. J. (1990). The logic of regulative communication: Understanding the rationality of message designs. In J. P. Dillard (Ed.), Seeking compliance: The production of interpersonal influence messages (pp. 87-104). Scottsdale, AZ: Gorsuch Scarisbrick.

O’Keefe, B. J. (1992). Developing and testing rational models of message design. Human Communication Research, 18, 637-649.

Parks, M. R. (2007). Personal relationships and personal networks. Mahwah, NJ: Lawrence Erlbaum.

This is an Accepted Manuscript of an article published by Taylor \& Francis Group in Journal of Applied Communication Research on November 25, 2011, available online: http://dx.doi.org/10.1080/00909882.2011.636373 
Rankin-Esquer, L. A., Deeter, A. K., Froelicher, E., \& Taylor, C. B. (2000). Coronary heart disease: Intervention for intimate relationship issues. Cognitive and Behavioral Practice, 7, 212-220.

Rolland, J. S. (1994). In sickness and in health: The impact of illness on couples' relationships. Journal of Marital and Family Therapy, 20, 327-347.

Sher, T. G. and Baucom, D. H. (2001). Mending a broken heart: A couples approach to cardiac risk reduction. Applied and Preventive Psychology, 10, 125-133.

Shoham, V., Rohrbaugh, M. J., Trost, S. E., \& Muramoto, M. (2006). A family consultation intervention for health-compromised smokers. Journal of Substance Abuse Treatment, 31, 395-402.

Strauss, A., \& Corbin, J. (1998). Basics of qualitative research: Techniques and procedures for developing grounded theory, 2ed. Newbury Park, CA: Sage.

Tracy, K. (2008). Action-implicative discourse analysis theory. In L. A. Baxter, \& D. O. Braithwaite (Eds.), Engaging theories in interpersonal communication: Multiple perspectives (pp. 149-160). Los Angeles, CA: Sage.

Tucker, J. S., \& Anders, S. L. (2001). Social control of health behaviors in marriage. Journal of Applied Social Psychology, 31, 467-485.

Tucker, J. S., \& Mueller, J. S. (2000). Spouses' social control of health behaviors: Use and effectiveness of specific strategies. Personality and Social Psychology Bulletin, 26, 11201130.

Wilmot, W. W. (1980). Meta-communication: A re-examination and extension. In D. Nimmo (Ed.), Communication Yearbook 4 (pp. 61-69). New Brunswick, NJ: Transaction.

This is an Accepted Manuscript of an article published by Taylor \& Francis Group in Journal of Applied Communication Research on November 25, 2011, available online: http://dx.doi.org/10.1080/00909882.2011.636373 
This is an Accepted Manuscript of an article published by Taylor \& Francis Group in Journal of Applied Communication Research on November 25, 2011, available online:

http://dx.doi.org/10.1080/00909882.2011.636373 


\section{Notes}

${ }^{1}$ We have given all participants pseudonyms to protect their privacy.

${ }^{2}$ As this case shows, an example can be categorized into more than one type of strategy. Wording one's comment as an inquiry counts as saying it nicely; when the inquiry receives an answer and the inquirer chooses not to pursue the topic further, this also entails rationing talk.

${ }^{3}$ For example, Shoham, Rohrbaugh, Trost, and Muramoto (2006) use systems-based couples therapy to address smoking and Sher and Baucom (2001) describe group cognitive-behavioral couple therapy for lifestyle change.

${ }^{4}$ Many communication theories focus on strategies in response to conflicting goals, so these refinements to Goldsmith’s theory likely have widespread application. Space limitations preclude a full comparison or exploration of other theories. 
Table 1. Summary of Communication Strategies for Managing Meanings and Dilemmas

\begin{tabular}{|c|c|c|c|}
\hline Strategy & Advantages & Disadvantages & When it worked best \\
\hline $\begin{array}{l}\text { Rationing talk, } \\
\text { including: } \\
\text {-- being selective } \\
\text {--saying it once } \\
\text {--patient initiates topic } \\
\text {--going along } \\
\text {--monitoring a } \\
\text { threshold) }\end{array}$ & $\begin{array}{l}\text {--Talking less } \\
\text { minimizes risks of } \\
\text { talk } \\
\text {--Respects autonomy, } \\
\text { difference }\end{array}$ & $\begin{array}{l}\text {--Restricting } \\
\text { expression can be } \\
\text { stressful } \\
\text {--Limits chances for } \\
\text { problem-solving } \\
\text { discussion } \\
\text {--Could be seen as } \\
\text { lack of concern }\end{array}$ & $\begin{array}{l}\text {--Meta- } \\
\text { communication at } \\
\text { some point to } \\
\text { clarify interpretation } \\
\text { of rationing }\end{array}$ \\
\hline $\begin{array}{l}\text { Saying it nicely, } \\
\text { including: } \\
\text {--conventional } \\
\text { indirectness } \\
\text {--inquiries and } \\
\text { suggestions } \\
\text {--routine exchanges } \\
\text {--joking } \\
\text {--substituting } \\
\text { nonverbal }\end{array}$ & $\begin{array}{l}\text {--Intentions can be } \\
\text { inferred without } \\
\text { threatening own or } \\
\text { other identity or } \\
\text { relationship } \\
\text {--Emphasizes rapport, } \\
\text { invites participation }\end{array}$ & $\begin{array}{l}\text {--Lack of clarity risks } \\
\text { misinterpretation of } \\
\text { intentions } \\
\text {--Clarifying } \\
\text { misinterpretation } \\
\text { heightens risks of } \\
\text { talk }\end{array}$ & $\begin{array}{l}\text {--Patient is fairly } \\
\text { compliant and both } \\
\text { share interpretation } \\
\text { of indirect strategy }\end{array}$ \\
\hline $\begin{array}{l}\text { Framing it } \\
\text { cooperatively, } \\
\text { including: } \\
\text {--problem-solving } \\
\text { discussion } \\
\text {--meta-communication } \\
\text {--acknowledging } \\
\text {--praising }\end{array}$ & $\begin{array}{l}\text {--Symmetrical roles } \\
\text { and/or agreement } \\
\text { mitigate } \\
\text { interpretations of } \\
\text { criticism or control } \\
\text {--Sense of } \\
\text { accomplishment } \\
\text { counteracts identity } \\
\text { loss }\end{array}$ & $\begin{array}{l}\text {--If results of } \\
\text { cooperation fail, } \\
\text { there is more at } \\
\text { stake for both } \\
\text { people } \\
\text {--Meta- } \\
\text { communicating or } \\
\text { acknowledging } \\
\text { desire could } \\
\text { emphasize how life } \\
\text { has changed } \\
\text {--Praise could be } \\
\text { condescending }\end{array}$ & $\begin{array}{l}\text {--Agreement on } \\
\text { compliance goals } \\
\text { and reciprocity of } \\
\text { framing } \\
\text {--Frame is already } \\
\text { familiar }\end{array}$ \\
\hline
\end{tabular}

This is an Accepted Manuscript of an article published by Taylor \& Francis Group in Journal of Applied Communication Research on November 25, 2011, available online:

http://dx.doi.org/10.1080/00909882.2011.636373 
Figure 1. Relationships Among Communication Strategies, Interpretive Lenses, and Environmental Resources.

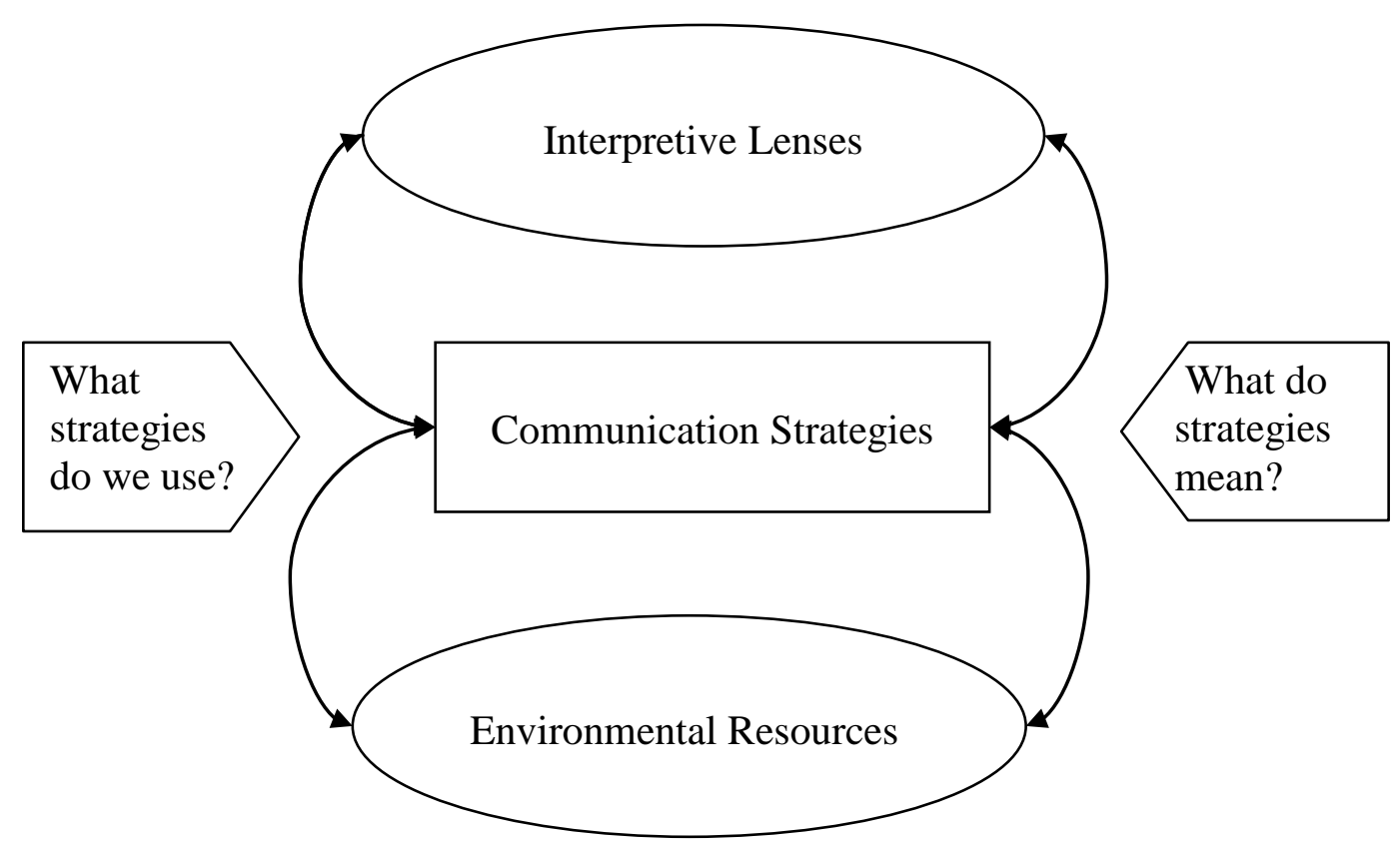

This is an Accepted Manuscript of an article published by Taylor \& Francis Group in Journal of Applied Communication Research on November 25, 2011, available online: http://dx.doi.org/10.1080/00909882.2011.636373 